\title{
Hypogammaglobulinemia as a Predictive Factor of Postoperative Complications in Pediatric Cardiac Surgery
}

\author{
Journal of Bioscience \& Biomedical Engineering
}

Original Article

Juliana Torres Pacheco ${ }^{1}$, Douglas Rossoni ${ }^{2 *}$, Rodrigo Moreira Castro ${ }^{2}$, Ana Paula Pantoja Margeotto ${ }^{3}$, Anita L R Saldanha ${ }^{3}$, Tania Leme da Rocha Martinez ${ }^{3}$ and Rodrigo Freire Bezerra ${ }^{2}$

\author{
*Correspondence authors \\ Douglas Rossoni \\ Rua Martiniano Carvalho 1049 \\ apto $114 \mathrm{C}$ \\ Bela Vista \\ São Paulo \\ $\mathrm{SP}$ \\ Brazil
}

${ }^{1}$ Intensive Care Unit, BP - A Beneficência Portuguesa de São Paulo, São Paulo, Brazil

${ }^{2}$ Cardiac Surgery Department, BP - A Beneficência Portuguesa de São Paulo, São Paulo, Brazil

${ }^{3}$ Nephrology Department, BP - A Beneficência Portuguesa de São Paulo, São Paulo, Brazil
Submitted : 4 Nov 2021 ; Published : 22 Nov 2021

\begin{abstract}
Introduction: Hypogammaglobulinemia, developed as a result of cardiac surgery accompanied by cardiopulmonary bypass (CPB), may be caused by hemodilution, destruction of immunoglobulin, extravasation into the interstitial space related to systemic inflammation, and capillary leak syndrome.

Therefore, to address this gap, we analyzed the characteristics of the infants who developed hypogammaglobulinemia after cardiac surgery and could benefit from Immunoglobulin supplementation.

Methods: This is a retrospective study evaluating infants undergoing surgery for repair of congenital heart defects from October 1, 2019 to June 30th, 2020 in the neonatal unit of our institution. Due to its retrospective design, informed consent was not required. Patients were divided in two groups: Group 1 (IgG>=340mg/dL) and Group $2(\operatorname{IgG}<340 \mathrm{mg} / \mathrm{dL})$. The value cut point was defined taking into consideration p10 level of Immunoglobulin according to Fujimura.

Results: From October 1, 2019 to June 30th, 2020, 62 children were born or admitted in our neonatal unit. Among them, 19 (30\%) have their IgG dosed, according to attending physician decision. Among patients with hypogammaglobulinemia, Pseudomonas sp was present in $87.5 \%$ of blood stream and/or tracheal secretion cultures. Regarding survival analysis, mortality was not different between Group 1 and 2.

Conclusion: Hypogammaglobulinemia has proved to be a predictor factor of postoperative complications in pediatric cardiac surgery. However, prospective trials are needed to determine the incidence of this problem, its real impact on survival, and the appropriate therapy.
\end{abstract}

\section{Introduction}

Hypogammaglobulinemia, developed as a result of cardiac surgery accompanied by cardiopulmonary bypass (CPB), may be caused by hemodilution, destruction of immunoglobulin, extravasation into the interstitial space related to systemic inflammation, and capillary leak syndrome [1,2]. Normally, neonatal serum immunoglobulin $\mathrm{G}$ ( $\mathrm{IgG}$ ) levels could be equal to or slightly higher than maternal serum IgG levels, gradually falling by three months of age and progressively increasing as IgG synthesis becomes established [3]. IgG levels for infants who have undergone cardiac surgery, however, have decreased about 45 percent when compared with preoperative concentrations [4]. Reduction in IgG levels may also be sustained for several days post-CPB $[1,5]$.

Because immunoglobulin $\mathrm{G}$ is an integral component of the humoral immune system, acquired hypogammaglobulinemia may increase risk of secondary infection $[1,6]$. In primary antibody deficiency, supplementation of intravenous immunoglobulins [7] is an accepted standard of practice and results in significant reduction in infections [8]. However, there is no consensus regarding hypogammaglobulinemia following the repair of congenital heart defects.

Therefore, to address this gap, we analyzed the characteristics of the infants who developed hypogammaglobulinemia after cardiac surgery and could benefit from Immunoglobulin supplementation. 


\section{Methods}

\section{Patients and Data Collection}

This is a retrospective study evaluating infants undergoing surgery for repair of congenital heart defects from October 1, 2019 to June 30th, 2020 in the neonatal unit of our institution. Due to its retrospective design, informed consent was not required. We evaluated all patients admitted to the Cardiac Intensive Care Unit (CICU) in whom an IgG level was obtained. The decision to obtain an IgG level was made by the attending physician.

Primary endpoint was mortality rate at the studied population. All other demographic, clinical, and laboratory data were obtained from our institutional clinical database, including length of stay in the CICU, weight, albumin levels, length of peritoneal dialysis (PD) and CPB and necessity of Extracorporeal Membrane Oxygenation (ECMO). Frequency of infection was analyzed together with the microbiota analysis of tracheal secretion and blood stream cultures. Length of ICU stay was divided in (1) less than 30 days, (2) 30-60 days and (3) more than 60 days, length of PD was divided in (1) less than 7 days, (2) 7-14 days and (3) more than 14 days, and length of cardiopulmonary bypass could be (1) $<100$ minutes, (2) 100-200 minutes or (3) $>200$ minutes.

\section{Immunoglobulin Analysis}

All IgG concentrations were determined using the Fusion 5.1 analyzer (Ortho Clinical Diagnostics, Rochester, NY) in our institutional clinical laboratory.

Patients were divided in two groups: Group 1 ( $\mathrm{IgG}>=340 \mathrm{mg} /$ $\mathrm{dL})$ and Group $2(\mathrm{IgG}<340 \mathrm{mg} / \mathrm{dL})$. The value cut point was defined taking into consideration p10 level of Immunoglobulin according to Fujimura [9].

\section{Intraoperative and Postoperative Management}

The CPB circuit was primed with $25 \%$ albumin, plasmalyte $^{\circledR}$, and sodium bicarbonate. Adose of $40 \mathrm{mg}$ of methylprednisolone, $1 \mathrm{ml}$ of calcium chloride, and $3 \mathrm{ml} / \mathrm{kg}$ of mannitol were given during CPB. Packed red blood cells were added to the CPB circuit to maintain the desired hematocrit. Del Nido cardioplegia $(20 \mathrm{ml} / \mathrm{kg})$ was used for aortic crossclamping. Postoperative management depended on the cardiac disease and management target specific hemodynamic and respiratory goals via inotrope and vasodilator titration, colloid boluses, and ventilator adjustments.

During the first 24 hours, we followed a fluid-restrictive protocol including $30 \mathrm{ml} / \mathrm{kg}$ maintenance intravenous fluids. Patients submitted to Norwood Sano procedure received prophylactic peritoneal dialysis catheter, which was initiated if positive fluid balance. Oncotic pressure was maintained with $25 \%$ albumin $(1 \mathrm{~g} / \mathrm{kg})$ if serum albumin was $<3.5 \mathrm{~g} / \mathrm{dL}$.

\section{Statistical Analysis}

SPSS, version 21 (IBM, Chicago, Ill), was used for all statistical analysis. Continuous variables not normally distributed were summarized as a median. Categorical data were compared using the Fisher exact test. $\mathrm{P}<0.05$ was considered statistically significant. All statistical tests were 2-tailed. Survival analysis was performed using Kaplan-Meyer curve and compared according to log rank test.

\section{Results}

From October 1, 2019 to June 30th, 2020, 62 children were born or admitted in our neonatal unit. Among them, 19 (30\%) haver their $\operatorname{IgG}$ dosed, according to attending physician decision (Figure 1). Patients characteristics are expressed in Table 1 and 2.

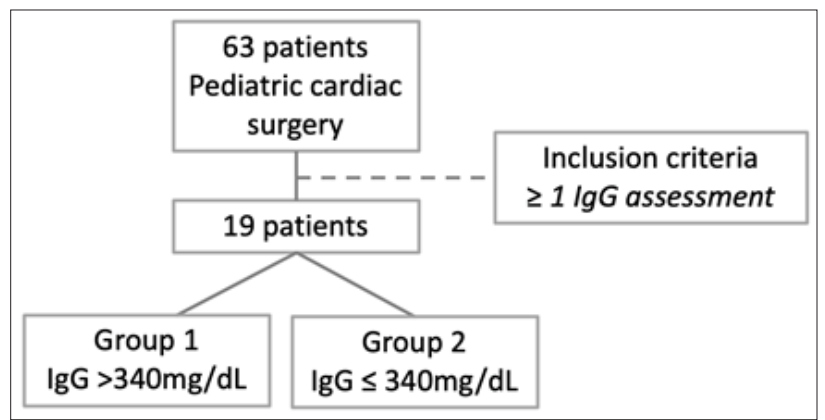

Figure 1: Consort distribution

\begin{tabular}{|c|c|c|c|}
\hline & $\begin{array}{l}\text { Group } 1 \\
(\mathrm{IgG}> \\
340 \mathrm{mg} / \\
\mathrm{dL}) \\
\mathrm{N},(\%)\end{array}$ & $\begin{array}{l}\text { Group } 2 \\
(\mathrm{IgG}< \\
340 \mathrm{mg} / \\
\mathrm{dL}) \\
\mathrm{N},(\%)\end{array}$ & $\begin{array}{l}\text { Total } \\
\mathrm{N},(\%)\end{array}$ \\
\hline Number of patients & $3(100)$ & $16(100)$ & 19(100) \\
\hline Weight (Kg, median) & 2.65 & 3.11 & 3.01 \\
\hline \multicolumn{3}{|l|}{ Gender } & $19(100)$ \\
\hline Male & $1(33)$ & $8(50)$ & $9(47)$ \\
\hline Female & $2(67)$ & $8(50)$ & $10(53)$ \\
\hline $\begin{array}{l}\text { Gestational age } \\
\text { (weeks, median) }\end{array}$ & 38 & $383 / 7$ & $382 / 7$ \\
\hline Age (days, median) & 14 & 7 & 7 \\
\hline \multicolumn{4}{|l|}{ RACHS-1 category } \\
\hline Category 1 & 0 & 0 & 0 \\
\hline Category 2 & 0 & $2(12.5)$ & $2(10.5)$ \\
\hline Category 3 & $3(100)$ & $5(31)$ & $8(42.1)$ \\
\hline Category 4 & 0 & 0 & 0 \\
\hline Category 5 & 0 & 0 & 0 \\
\hline Category 6 & 0 & $9(56.5)$ & $9(47.4)$ \\
\hline
\end{tabular}

Table 1 : Patients characteristics (continuous variables) 


\begin{tabular}{|c|c|c|c|c|}
\hline & Group 1 & \begin{tabular}{|l|} 
Group 2 \\
\end{tabular} & Total & p-value \\
\hline Total & $3(100)$ & $16(100)$ & $19(100)$ & \\
\hline \multicolumn{5}{|l|}{ Weight } \\
\hline$<2000 \mathrm{~g}$ & $0(0.0)$ & $3(18.8)$ & $3(15.8)$ & $p=0.332$ \\
\hline $2000-3000 \mathrm{~g}$ & $2(66.7)$ & $4(25.0)$ & $6(31.6)$ & \\
\hline$>3000 \mathrm{~g}$ & $1(33.3)$ & $9(56.3)$ & $\begin{array}{l}10 \\
(52.6)\end{array}$ & \\
\hline \multicolumn{5}{|c|}{ Hypoalbuminemia $(<3.5 \mathrm{~g} / \mathrm{dL})$} \\
\hline Yes & $2(66.7)$ & $16(100)$ & $\begin{array}{l}18 \\
(94.7)\end{array}$ & $\mathrm{p}=0.018$ \\
\hline No & $1(33.3)$ & $0(0.0)$ & $1(5.3)$ & \\
\hline \multicolumn{5}{|c|}{ Time of peritoneal dialysis } \\
\hline$<7$ days & $2(66.7)$ & $4(25.0)$ & $6(31.6)$ & $\mathrm{p}=0.283$ \\
\hline 7-14 days & $1(33.3)$ & $6(37.5)$ & $7(36.8)$ & \\
\hline$>14$ & $0(0.0)$ & $6(37.5)$ & $6(31.6)$ & \\
\hline \multicolumn{5}{|c|}{ ICU length of stay } \\
\hline$<30$ days & $3(100)$ & $4(25)$ & $7(36.8)$ & $p=0.047$ \\
\hline 30-60 days & $0(0.0)$ & $7(43.8)$ & $7(36.8)$ & \\
\hline$>60$ days & $0(0.0)$ & $5(31.3)$ & $5(26.3)$ & \\
\hline \multicolumn{5}{|c|}{ CEC (minutes) } \\
\hline 100 & $3(100)$ & $1(6.3)$ & $4(21.1)$ & $p=0.001$ \\
\hline $100-200$ & $0(0.0)$ & $10(62.5)$ & $\begin{array}{l}10 \\
(52.6)\end{array}$ & \\
\hline$>200$ & $0(0.0)$ & $5(31.3)$ & $5(26.3)$ & \\
\hline \multicolumn{5}{|l|}{ ECMO } \\
\hline Yes & $0(0.0)$ & $8(50.0)$ & $8(42.1)$ & $p=0.107$ \\
\hline No & $3(100)$ & $8(50.0)$ & $\begin{array}{l}11 \\
(57.9)\end{array}$ & \\
\hline \multicolumn{5}{|l|}{ Infection } \\
\hline None & $2(66.7)$ & $1(6.3)$ & $3(15.8)$ & $p=0.006$ \\
\hline $\begin{array}{l}\text { Gram } \\
\text { positive }\end{array}$ & $1(33.3)$ & $1(6.3)$ & $2(10.5)$ & \\
\hline $\begin{array}{l}\text { Gram } \\
\text { negative }\end{array}$ & $0(0.0)$ & $14(87.5)$ & $\begin{array}{l}14 \\
(73.7)\end{array}$ & \\
\hline
\end{tabular}

Table 2 : Patients characteristics (categorical variables)

Among patients with hypogammaglobulinemia, Pseudomonas sp was present in $87.5 \%$ of blood stream and/or tracheal secretion cultures.

Regarding survival analysis, mortality was not different between Group 1 and 2 (Figure 2).

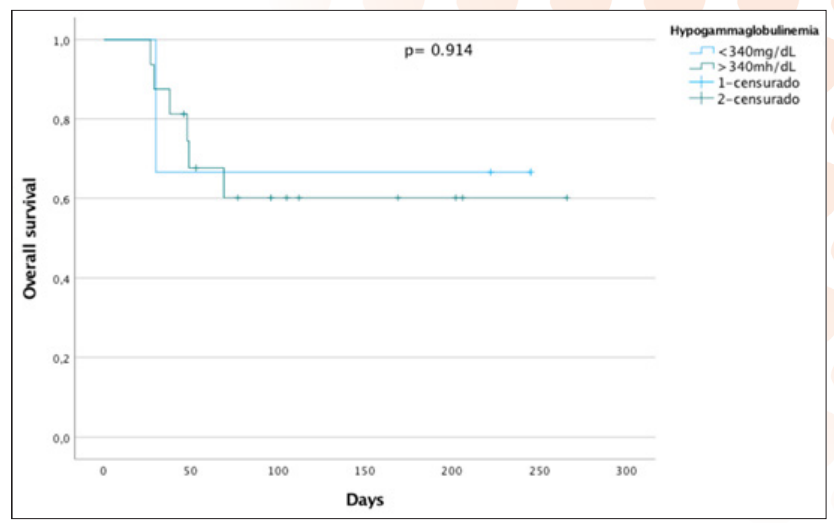

Figure 2 : Overall survival analysis between groups $1(\operatorname{IgG}>=$ $340 \mathrm{mg} / \mathrm{dL})$ and $2(\mathrm{IgG}<340 \mathrm{mg} / \mathrm{dL})$

\section{Discussion}

We have found that hypogammaglobulinemia is a predictor factor to cardiac postoperative complications as infections and length of stay in ICU. It's also associated with hypoalbuminemia and prolonged cardiopulmonary bypass.

Hypogammaglobulinemia after CPB is a known complication, but mechanisms are not totally understood. Some authors have attributed these changes to hemodilution during CPB [10]. However, Hoskote et al [8] have found that Ig concentration continued to fall during a period of significant hemoconcentration (mean net fluid balance negative 50 $\mathrm{ml} / \mathrm{kg}$ ) and proposed that extravasation into the interstitial compartment due to increased capillary permeability, and/ or losses in urine, pleural fluid, or peritoneal fluid could be additional sources of ongoing IgG losses. Besides, IgG is regenerated at a slower rate than complement levels postoperatively $[11,12]$, especially in neonates who have the IgG serum levels according to transplacental transmission.

Since our research was conducted in a retrospective design, we could not affirm the real etiology factors involved, nevertheless the majority of our surgeries presented a prolonged time of cardiopulmonary bypass, which is already proven to be related to an increased systemic inflammatory response syndrome [7]. And according to Rhodes et al, SIRS may contribute to hypogammaglobulinemia via capillary leak of $\mathrm{IgG}$ losses into the interstitium and SIRS-associated volume resuscitation requirements [1].

All of our patients with hypogammaglobulinemia also presented low serum albumin levels, possibly indicating that SIRS and capillary leak are involved in both protein losses, despite the fact that its molecular weight is more than twice that of albumin [13].

The profound changes in both humoral and cellular immune function after CPB regarding the sustained reduction in $\operatorname{IgG}$ may be associated with several adverse clinical outcomes, including fluid overload, longer duration of mechanical ventilation, and longer CICU length of stay [1]. We have not found relation between duration of mechanical ventilation and 
lower Immunoglobulin $\mathrm{G}$, however $75 \%$ of our patients with IgG $<340 \mathrm{mg} / \mathrm{dL}$ presented a CICU length of stay above 30 days.

The immunoglobulin $\mathrm{G}$ class is responsible for $70 \%$ to $75 \%$ of the total immunoglobulin pool. Its deficiency has been associated with increased susceptibility to infection [13], what could be proved by our data that showed $93.7 \%$ of patients in the hypogammaglobulinemia group with evidence of infection, either in blood stream or tracheal secretion culture.

In primary antibody deficiency, supplementation of intravenous immunoglobulins [7] is an accepted standard of practice and results in significant reduction in infections, however the role of IVIg in secondary immune deficiency is unclear $[8,14]$.

In low-birth-weight neonates, there is some evidence that prophylactic IVIg can reduce the risk of severe bloodstream infections [11,12] and reduce mortality in those with earlyonset neonatal sepsis, but literature is scarce regarding postoperative hypogammaglobulinemia. Problems with IVIG administration include cost, the potential for anaphylactoid reactions, and issues regarding volume overload [13].

A randomized, prospective, placebo-controlled, double-blind study, which was conducted in 11 cardiothoracic centers in Germany, showed that in most cases of adult patients undergoing cardiac surgery involving cardiopulmonary bypass, SIRS is mild, transient, and without a negative effect on prognosis. Even so, patients who develop severe SIRS derived no improvement in short-term morbidity or 28-day mortality from IVIg [7]. However, the pediatric population may not behave the same way, especially infants. In our population, $56.6 \%$ of patients with hypogammaglobulinemia were submitted to a surgery category 6 of Risk Adjustment for Congenital Heart Surgery 1 (RACHS-1), that is Norwood Sano procedure, and more than $90 \%$ presented a CPB above 100 minutes, what probably indicates a greater need of Immunoglobulin administration. Stiehm et al [15] reported a statistically significant benefit of IVIG in a meta-analysis regarding IVIG administration to pediatric patients with primary and secondary IgG deficiencies. The rationale for IVIg treatment is that immunoglobulins provide immunomodulatory effects, in addition to antibody cover, with activation of complement, increase in neutrophil counts and function, improvement of opsonin activity, endotoxin inhibition, and modulation of proinflammatory cytokines, all necessary requirements for a baby after cardiac surgery [8].

Even though we have found a possible advantage of IgG administration regarding blood stream infection and/or pneumonia related to mechanical ventilation, we could not prove a statistically significant impact on overall survival. There wasn't also any relationship when we analyzed patient's weight, malnutrition, time of peritoneal dialysis and evolution to ECMO support. The size of our sample may be one of the reasons involved in these results. Together with the retrospective character that limits our analysis and data interpretation, it might be the most important limitation to consider in this paper.

\section{Conclusion}

Hypogammaglobulinemia has proved to be a predictor factor of postoperative complications in pediatric cardiac surgery. Understanding the behavior of immunoglobulin in infants after cardiopulmonary bypass is essential to promote IVIg as an early intervention to reduce short-term morbidity or 28-day mortality. However, prospective trials are needed to determine the incidence of this problem, its real impact on survival, and the appropriate therapy.

This study was carried out at Hospital Beneficência Portuguesa de São Paulo, São Paulo, SP, Brazil.

\section{Conflcit}

No conflict of interest.

Funding

No financial support.

\section{References}

1. Rhodes LA, Robert SM, Atkinson TP, Dabal RJ, Mahdi AM, Alten JA. (2014). Hypogammaglobulinemia after cardiopulmonary bypass in infants. $J$ Thorac Cardiovasc Surg, 147(5), 1587-1593 e1.

2. Seghaye MC, Grabitz RG, Duchateau J, Busse S, Dabritz S, Koch D, et al. (1996). Inflammatory reaction and capillary leak syndrome related to cardiopulmonary bypass in neonates undergoing cardiac operations. $J$ Thorac Cardiovasc Surg, 112(3), 687-697.

3. Stiehm ER, Fudenberg HH (1966). Serum levels of immune globulins in health and disease: a survey. Pediatrics, 37(5), 715-727.

4. Gandhi JG, Salm TV, Szymanski I (1983). Effect of cardiopulmonary bypass on plasma fibronectin, $\mathrm{IgG}$, and C3. Transfusion, 23(6), 476-479.

5. Hauser GJ, Chan MM, Casey WF, Midgley FM, Holbrook PR (1991). Immune dysfunction in children after corrective surgery for congenital heart disease. Crit Care Med, 19(7), 874-881.

6. Yamani MH, Narayan SB, Haire C, Hobbs R (2007). Hypogammaglobulinemia in heart failure patients: prevalence and impact on infectious outcomes. $J$ Heart Lung Transplant, 26(12), 1350-1351.

7. Werdan K, Pilz G, Muller-Werdan U, Maas Enriquez M, Schmitt DV, Mohr FW, et al. (2008). Immunoglobulin $\mathrm{G}$ treatment of postcardiac surgery patients with scoreidentified severe systemic inflammatory response syndrome--the ESSICS study. Crit Care Med, 36(3), 716723.

8. Hoskote AU, Ramaiah RN, Cale CM, Hartley JC, Brown KL. (2012). Role of immunoglobulin supplementation for secondary immunodeficiency associated with chylothorax after pediatric cardiothoracic surgery. Pediatr Crit Care Med, 13(5), 535-541.

9. Fujimura DM. (1990). Serum levels of immunoglobulin G subclasses in normal and nephrotic children. Doctoral thesis. 1990.

10. van Velzen-Blad H, Dijkstra YJ, Schurink GA, Verbrugh HA, Verhoef J, Zegers BJ, et al. (1985). Cardiopulmonary 
bypass and host defense functions in human beings: I. Serum levels and role of immunoglobulins and complement in phagocytosis. Ann Thorac Surg, 39(3): 207-211.

11. Provan D, Chapel HM, Sewell WA, O'Shaughnessy D, Group UKIEW (2008). Prescribing intravenous immunoglobulin: summary of Department of Health guidelines. $B M J, 337$, a1831.

12. Jenson HB, Pollock BH (1997) Meta-analyses of the effectiveness of intravenous immune globulin for prevention and treatment of neonatal sepsis. Pediatrics, 99(2), E2.

13. Rehman S, Bytnar D, Berkenbosch JW, Tobias JD (2003) Hypogammaglobulinemia in pediatric ICU patients. $J$ Intensive Care Med, 18(5), 261-264.

14. Wood P, Stanworth S, Burton J, Jones A, Peckham DG, Green T, et al. (2007). Recognition, clinical diagnosis and management of patients with primary antibody deficiencies: a systematic review. Clin Exp Immuno, 149(3), 410-423.

15. Stiehm ER (1997). Human intravenous immunoglobulin in primary and secondary antibody deficiencies. Pediatr Infect Dis J, 16(7), 696-707.

Copyright: (C2021 Douglas Rossoni. This is an open-access article distributed under the terms of the Creative Commons Attribution License, which permits unrestricted use, distribution, and reproduction in anymedium, provided the original author and source are credited. 